\title{
Renal Tubular Transport of Organic Acids
}

\author{
STUDIES WITH OXALATE AND PARA-AMINOHIPPURATE IN THE RAT
}

\author{
E. J. Weinman, S. J. Frankfurt, A. Ince, and S. Sansom, Renal Section, \\ Department of Medicine, Veterans Administration Hospital and Baylor College of \\ Medicine, Houston, Texas 77211
}

A BSTRACT The renal handling of oxalate was examined by free-flow micropuncture, intratubular microinjection, and droplet precession techniques in the rat. After the sustained i.v. infusion of $\left[{ }^{14} \mathrm{C}\right]$ oxalate, the fractional delivery of oxalate from the early portions of the proximal tubule was $120.1 \pm 4.4 \%$, indicating net secretion. Fractional delivery rates from the late proximal tubule $(124.6 \pm 6.1)$, distal tubule $(120.9 \pm 2.9)$, and final urine $(126.2 \pm 2.9 \%)$ were not different from that of the early proximal tubule. Direct intratubular microinjections of oxalate into the early proximal tubule and late proximal tubule yielded urinary recovery rates of $85 \pm 3 \%$ and $101 \pm 2 \%$, respectively, suggesting that oxalate absorption does occur in the mid-portions of the proximal tubule. Droplet precession studies confirmed a secretory flux for oxalate. In contrast to oxalate, para-aminohippurate (PAH), the more traditional marker for organic acid transport, was secreted in the late portions of the proximal tubule and in large measure at a site between the late proximal and distal tubules, presumably the pars recta. Probenecid inhibited PAH secretion but was without effect on net oxalate transport, oxalate absorption, or oxalate secretion.

These studies demonstrate that net oxalate secretion occurs in the early portions of the proximal convoluted tubule, undergoes bidirectional transport of approximately equal magnitude in later segments of the proximal tubule, and probably is not transported in more distal nephron sites. The secretory mechanism for oxalate differs from that of PAH in that it is located in a different segment of the nephron and is not inhibited by probenecid. These differences

These studies were performed while Dr. Frankfurt was a Fellow in Nephrology of Baylor College of Medicine. This work was supported in part by a Clinical Investigatorship award to Dr. Weinman and an Associate Investigatorship award to Dr. Frankfurt from the Veterans Administration.

Received for publication 26 August 1977 and in revised form 21 October 1977. suggest that the early portions of the proximal tubule are important in the renal metabolism of some organic acids.

\section{INTRODUCTION}

Para-aminohippurate $(\mathrm{PAH})^{1}$ has been extensively used as a marker to examine the ability of the kidney to secrete organic acids (1-3). Although bidirectional movement of PAH may be demonstrated in the proximal convoluted tubule, free-flow micropuncture studies have indicated that net secretion of this organic acid occurs between the late portion of the proximal convoluted tubule and the distal tubule $(2$, 4-7). Isolated nephron studies in the rabbit kidney have shown that the pars recta is the major site of net secretion of PAH (1). The contribution of other nephron segments to the renal handling of other organic acids, on the other hand, has not been extensively studied. The current micropuncture studies were undertaken to examine the renal handling of the dicarboxylic acid, oxalate, and to compare its renal transport characteristics with that of PAH.

\section{METHODS}

All studies were performed on male Sprague-Dawley rats with free access to food and water before study. Anesthesia was induced with pentobarbital $(50-60 \mathrm{mg} / \mathrm{kg}$ body wt) injected intraperitoneally. A tracheostomy was performed, both jugular veins were cannulated, and the urinary bladder was catheterized. The left kidney was approached through a flank incision, the perirenal fat and capsule were removed, and the kidney was prepared for micropuncture, as previously described from this laboratory $(8,9)$. In the microinjection and droplet precession studies, the left ureter was catheterized with PE 50 tubing to permit separate urine collections from each kidney.

Free-flow studies. In the oxalate studies, a priming infusion of $1 \mathrm{ml}$ of a solution containing $\left[{ }^{3} \mathrm{H}\right]$ inulin ([methoxy$\left.{ }^{3} \mathrm{H}\right]$ inulin) $(75 \mu \mathrm{Ci} / \mathrm{ml})$ and $\left[{ }^{14} \mathrm{C}\right]$ oxalate $\left(\left[\mathrm{U}-{ }^{14} \mathrm{C}\right]\right.$ oxalic acid $)$

\footnotetext{
${ }^{1}$ Abbreviation used in this paper: $\mathrm{PAH}$, para-aminohippurate.
} 
(75 $\mu \mathrm{Ci} / \mathrm{ml}$ ) was given, followed by the sustained infusion of the same solution at a rate of $1.2 \mathrm{ml} / \mathrm{h}$. Where examined, probenecid was dissolved in a solution of $\mathrm{NaHCO}_{3}$ (30) $\mathrm{meq} / \mathrm{liter})(\mathrm{pH} 7.4)$ in a concentration calculated to deliver 100 $\mathrm{mg} / \mathrm{kg}$ body wt per $\mathrm{h}$ and was infused at a rate of $1.2 \mathrm{ml} / \mathrm{h}$. Control animals received an infusion of the diluent alone at the same rate.

In the PAH studies, the priming and sustaining isotope solution contained $\left[{ }^{3} \mathrm{H}\right]$ PAH (aminohippuric acid, $p$-[glycol$\left.\left.2-{ }^{3} \mathrm{H}\right]\right)(67 \mu \mathrm{Ci} / \mathrm{ml})$ and $\left[{ }^{14} \mathrm{C}\right]$ inulin ([carboxyl- $\left.{ }^{14} \mathrm{C}\right]$ inulin) $(67 \mu \mathrm{Ci} / \mathrm{ml})$ in isotonic saline. Animals were studied in a manner identical with that of the oxalate studies.

After $90 \mathrm{~min}$ of equilibration, free-flow micropuncture samples were obtained from proximal and distal nephron sites. Blood and urine samples were collected simultaneously. The clearance rates of inulin, oxalate, and PAH and the fractional excretion rates were calculated from standard formulas. The fractional delivery rates (FD) from the point of micropuncture were calculated from the expression

$$
\mathrm{FD}(\%)=\frac{\mathrm{TF} / \mathrm{P} \mathrm{X}}{\mathrm{TF} / \mathrm{P}_{\text {inulin }}} \times 100,
$$

where $\mathrm{X}$ indicates the disintegrations per minute $(\mathrm{dpm})$ in tubular fluid (TF) and plasma $(\mathrm{P})$ of either $\left[{ }^{14} \mathrm{C}\right]$ oxalate or $\left[{ }^{3} \mathrm{H}\right] \mathrm{PAH}$

Microinjection studies. Animals were prepared for study as indicated above, except that no isotopes were infused systemically. A solution of $5 \%$ mannitol in isotonic saline was infused at a rate of $12 \mathrm{ml} / \mathrm{h}$ to ensure high urine flow rates. The intratubular microinjection solutions contained either $\left[{ }^{14} \mathrm{C}\right]$ oxalate $(50 \mu \mathrm{Ci} / \mathrm{ml})$ and $\left[{ }^{3} \mathrm{H}\right]$ inulin $(50 \mu \mathrm{Ci} /$ $\mathrm{ml})$, or $\left[{ }^{3} \mathrm{H}\right] \mathrm{PAH}(50 \mu \mathrm{Ci} / \mathrm{ml})$ and $\left[{ }^{14} \mathrm{C}\right]$ inulin $(50 \mu \mathrm{Ci} / \mathrm{ml})$. Probenecid or diluent was infused as described in the free-flow studies. 10-12 $\mathrm{nl}$ of the microinjection solutions were microinjected over a 120-s interval into the early or late portions of the proximal convoluted tubule in the oxalate studies and into the early portion of the proximal tubule only in the PAH studies. After each microinjection, urine was collected sequentially from both left and right kidneys in 60-s aliquots. The procedures for microinjection, localization of micropuncture sites, and calculations of the fractional recovery rates in the urine have previously been described in detail from this laboratory (8).

Droplet precession studies. Animals were prepared as in the microinjection studies and received an i.v. infusion of $5 \%$ mannitol in isotonic saline at a rate of $12 \mathrm{ml} / \mathrm{h} .100$ $\mathrm{nl}$ of microinjection solution containing either $\left[{ }^{14} \mathrm{C}\right]$ oxalate and $\left[{ }^{3} \mathrm{H}\right]$ inulin or $\left[{ }^{3} \mathrm{H}\right] \mathrm{PAH}$ and $\left[{ }^{14} \mathrm{C}\right]$ inulin were placed upon the surface of the left kidney as a droplet, after which urines were collected from the left kidney in 20-s aliquots until the radioactivity of the urine had returned to background levels. Results are expressed as the ratio of the disintegrations per minute of the test substance to disintegrations per minute of inulin in the first urine sample to contain inulin, divided by the ratio of isotope counts in the droplet solution. A ratio of greater than 1 is taken as an index of secretion.

Radioactive $\left[{ }^{14} \mathrm{C}\right]$ oxalate (specific activity $578 \mu \mathrm{Ci} / \mathrm{mg}$ ) and $\left[{ }^{3} \mathrm{H}\right.$ ]PAH (specific activity $3.44 \mu \mathrm{Ci} / \mathrm{mg}$ ) were determined to be $99 \%$ pure by the manufacturers (Amersham/Searle Corp., Arlington Heights, Ill., and New England Nuclear, Boston, Mass., respectively). ${ }^{14} \mathrm{C}$ counts in the urine were assumed to be oxalate, since oxalate is a metabolic end product in mammals. This was confirmed by silica gel thinlayer chromatography using a 95:5:1 ethyl alcohol, water, ammonium hydroxide solvent system (8). The distribution of ${ }^{14} \mathrm{C}$ counts in the urine on the thin-layer plates was identical with that of the stock $\left[{ }^{14} \mathrm{C}\right]$ oxalate solution and in the same location of standard nonlabeled oxalate solutions. Lack of bacterial conversion of $\left[{ }^{14} \mathrm{C}\right]$ oxalate in stock solution was confirmed by comparing freshly prepared $\left[{ }^{14} \mathrm{C}\right]$ oxalate with solutions of $\left[{ }^{14} \mathrm{C}\right]$ oxalate maintained in the refrigerator for over 14 days. Using the same thin-layer system, the purity of the $\left[{ }^{3} \mathrm{H}\right] \mathrm{PAH}$ in urine and stock solutions was confirmed.

Radioactivity of the samples of blood, urine, tubular fluid, and microinjection solutions was determined in Biofluor (New England Nuclear) in a Packard Tri-Carb liquid scintillation counter (Packard Instrument Co., Inc., Downers Grove, Ill.). Counts per minute of each isotope were converted to disintegrations per minute after correction for quenching, efficiency of counting, and crossover counts. All data are expressed as the mean \pm SEM. Significance was determined by Student's $t$ test.

\section{RESULTS}

Oxalate. The results of free-flow micropuncture and clearance experiments in 11 control rats are summarized in Table $I$. The fractional excretion of oxalate in the final urine averaged $126.2 \pm 2.9 \%$ of the filtered load, indicating net secretion. Micropuncture samples obtained from the proximal tubule are grouped as early or late proximal tubule, with $\mathrm{TF} / \mathrm{P}_{\text {inulin }}$ values below 2 designated as an early proximal tubular site. The fractional delivery rates from the early proximal tubule averaged $120.1 \pm 4.4 \%$, a value not significantly different from that of the final urine. Samples obtained from the earliest portions of the proximal tubule $\left(\mathrm{TF} / \mathrm{P}_{\text {inulin }}<1.5\right)$ also averaged $118 \%(n=9)$ of the filtered load, suggesting that an oxalate secretory site exists in the immediate postglomerular segments not accessible to micropuncture in the species of rat utilized. Fractional delivery rates of oxalate from the late proximal tubule and from the distal convoluted tubule (124.6 \pm 6.1 and $120.9 \pm 2.9 \%$, respectively) were not significantly different from results obtained in the early proximal tubule or in the final urine.

To determine if bidirectional transport occurred in any segments of the nephron, microinjection studies into early and late portions of the proximal tubule were performed. As noted in Table III, $85 \pm 3 \%$ of oxalate microinjected into the early proximal tubule was recovered in the urine. Recoveries after microinjection into the later portions of the proximal tubule averaged $101 \pm 2 \%(P<0.01$ compared with the early proximal tubule). Droplet precession studies (Table IV) yielded ${ }^{14} \mathrm{C} /{ }^{3} \mathrm{H}:{ }^{14} \mathrm{C} /{ }^{3} \mathrm{H}$ urine to droplet ratio of counts of $5.2 \pm 0.7$, a value significantly above unity and indicative of oxalate secretion.

From these results, oxalate appears to be secreted in the earliest portions of the proximal convoluted tubule, undergoes bidirectional transport of approximately equal magnitude in the mid-portions of the proximal convoluted tubule, and is probably 
TABLE I

Free-flow Micropuncture and Clearance Results in Animals Receiving an Infusion of $\left[{ }^{14} \mathrm{C}\right]$ Oxalate*

\begin{tabular}{|c|c|c|c|}
\hline & Control $(n=11)$ & Probenecid $(n=8)$ & $P$ \\
\hline $\mathrm{GFR}, \mu l / \min$ per $g \mathrm{KW}$ & $996.1 \pm 39.9(31)$ & $917.6 \pm 58.0(17)$ & NS \\
\hline $\mathrm{C}_{\text {oxalate, }}, \mu l /$ min per $g \mathrm{KW}$ & $1262.1 \pm 70.4(31)$ & $1111.7 \pm 68.4(17)$ & NS \\
\hline $\mathrm{FE}_{\text {oxalate }}, \%$ & $126.2 \pm 2.9(31)$ & $122.4 \pm 3.3(17)$ & NS \\
\hline $\mathrm{U}_{\mathrm{Na}} \mathrm{V}, \mu e q / m i n$ per $g \mathrm{KW}$ & $0.11 \pm 0.03(31)$ & $0.11 \pm 0.01(17)$ & NS \\
\hline \multicolumn{4}{|l|}{ Proximal tubule } \\
\hline Early $T F / P_{\text {inulin }}$ & $1.68 \pm 0.04$ & $1.67 \pm 0.04$ & NS \\
\hline $\mathrm{FD}_{\text {oxalate }}$ & $120.1 \pm 4.4(30)$ & $120.3 \pm 3.2(24)$ & NS \\
\hline Late $T F / P_{\text {inulin }}$ & $2.40 \pm 0.07$ & $2.61 \pm 0.11$ & NS \\
\hline FD oxalate & $124.6 \pm 6.1(19)$ & $120.8 \pm 3.6(25)$ & NS \\
\hline \multicolumn{4}{|l|}{ Distal tubule } \\
\hline $\mathrm{TF} / \mathrm{P}_{\text {inulin }}$ & $7.6 \pm 0.69$ & - & \\
\hline $\mathrm{FD}_{\text {oxalate }}$ & $120.9 \pm 2.9(20)$ & - & \\
\hline
\end{tabular}

* Values expressed as mean $\pm \mathrm{SEM}$. $P$ indicates statistical comparison between values obtained in control animals and in animals receiving probenecid. NS = not significant. Numbers in parentheses indicate number of animals or number of samples analyzed. FD = fractional delivery from the point of micropuncture; $\mathrm{FE}=$ fractional excretion; $\mathrm{KW}$ = kidney weight.

not transported to a significant degree beyond the proximal convoluted tubule.

The effects of probenecid on the tubular handling of oxalate were examined in a separate group of rats and the results are summarized in Tables I, III, and IV. Probenecid did not significantly alter the fractional delivery rates of oxalate from early or late proximal tubule sites, did not inhibit oxalate efflux from the proximal tubule as determined by the results of the microinjection studies, and did not alter the urine to droplet ${ }^{14} \mathrm{C} /{ }^{3} \mathrm{H}$ ratio of counts in the precession studies.

$P A H$. To contrast the results obtained with oxalate, parallel studies were performed with PAH, the prototype compound used to examine the renal handling of organic acids. The results presented are not corrected for plasma binding of PAH. As can be seen in Table II, PAH secretion occurs predominantly in the late segments of the proximal convoluted tubule and at nephron sites between the late proximal

TABLE II

Free-flow Micropuncture and Clearance Results in Animals Receiving an Infusion of $\left[{ }^{3} \mathrm{H}\right] \mathrm{PAH}^{*}$

\begin{tabular}{|c|c|c|c|}
\hline & Control $(n=13)$ & Probenecid $(n=10)$ & $P$ \\
\hline GFR, $\mu l / \min$ per $g \mathrm{KW}$ & $941.2 \pm 46.4(30)$ & $1004.5 \pm 69.9(24)$ & NS \\
\hline $\mathrm{C}_{\mathrm{PAH}}, \mu l / m i n$ per $g K W$ & $1508.6 \pm 90.8(30)$ & $890.4 \pm 53.14(24)$ & $<0.001$ \\
\hline $\mathrm{FE}_{\mathrm{PAH}}, \%$ & $161.2 \pm 5.47(30)$ & $86.5 \pm 2.2(24)$ & $<0.001$ \\
\hline $\mathrm{U}_{\mathrm{Na}} \mathrm{V}, \mu e q / \min$ per $\mathrm{KW}$ & $0.09 \pm 0.01(30)$ & $0.11 \pm 0.02(24)$ & NS \\
\hline \multicolumn{4}{|l|}{ Proximal tubule } \\
\hline Early $\mathrm{TF} / \mathrm{P}_{\text {inulin }}$ & $1.63 \pm 0.04$ & $1.62 \pm 0.06$ & NS \\
\hline $\mathrm{FD}_{\mathrm{PAH}}$ & $88.7 \pm 3.7(24)$ & $80.7 \pm 2.6(21)$ & NS \\
\hline Late $T F / P_{\text {inulin }}$ & $2.59 \pm 0.07$ & $2.57 \pm 0.09$ & NS \\
\hline FD $_{\text {PAH }}$ & $114.9 \pm 4.5(29)$ & $83.8 \pm 2.0(25)$ & $<0.001$ \\
\hline \multicolumn{4}{|l|}{ Distal tubule } \\
\hline$T F / P_{\text {inulin }}$ & $11.5 \pm 1.57$ & $13.9 \pm 1.7$ & NS \\
\hline $\mathrm{FD}_{\mathrm{PAH}}$ & $164.5 \pm 8.4(20)$ & $84.5 \pm 2.3(20)$ & $<0.001$ \\
\hline
\end{tabular}

* See Table I for legend. 
tubule and distal tubule, presumably the pars recta. The fractional delivery rate of $\mathrm{PAH}$ from the distal tubule $(164.5 \pm 8.4 \%)$ was significantly higher than that obtained from late proximal tubular sites $(P$ $<0.01$ ), but not significantly different from that of the final urine.

Recoveries of PAH microinjected in the early portions of the proximal tubule averaged $98 \pm 1 \%$ (Table II), while the $\mathrm{PAH} /$ inulin urine/droplet ratio of counts was $28.3 \pm 3.1$, indicating a secretory flux (Table IV). In contrast to the results obtained with oxalate, probenecid had significant effects on the renal handling of PAH (Tables II, III, and IV). In animals receiving probenecid, the fractional delivery rates of PAH from early and late proximal sites $(80.7 \pm 2.6$ and $83.8 \pm 2.0 \%$ ) were not significantly different from each other or from the values obtained in the distal convoluted tubule $(84.5 \pm 2.3 \%)$ or in the final urine $(86.5 \pm 2.2 \%)$. These results indicate that probenecid markedly inhibited net PAH secretion, and were confirmed in the droplet precession studies where probenecid significantly reduced the $\mathrm{PAH} / \mathrm{inulin}$ urine/droplet ratio of counts to $2.8 \pm 0.5(P<0.001$ compared with controls).

\section{DISCUSSION}

Despite its clinical importance, the renal handling of oxalate has received only limited attention in the published literature. We are unaware of any prior studies of the type reported in this communication, which examines the segmental nephron contribution to net oxalate transport by the kidney. The current studies in the rat confirm the findings in man, sheep, and dog that oxalate is secreted by the mammalian kidney such that its fractional excretion in the final urine is greater than $100 \%$ of the filtered load (10-12). The values for oxalate excretion obtained in clearance and micropuncture studies were not corrected for plasma binding of oxalate, since preliminary studies in this and other laboratories sug-

TABLE III

Microinjection Studies (\% Recovery)*

\begin{tabular}{lcccc}
\hline & & Control & Probenecid & $P$ \\
\hline Oxalate & EPT & $85 \pm 3(10)$ & $86 \pm 1(13)$ & NS \\
& LPT & $101 \pm 2(9)$ & $99 \pm 2.8(6)$ & NS \\
\multirow{2}{*}{ PAH } & EPT & $98 \pm 1(18)$ & $100 \pm 3(12)$ & NS \\
& LPT & - & - & \\
\hline
\end{tabular}

* Values expressed as mean $\pm S E M$; numbers in parentheses indicate number of microinjections; $P$ indicates statistical comparison in control animals versus animals receiving probenecid. NS = not significant; $\mathrm{EPT}=$ early proximal tubule; LPT = late proximal tubule.
TABLE IV

Droplet Precession Studies (Ratio of Counts at the Arrival Time of Inulin)*

\begin{tabular}{lrcc}
\hline & Control & Probenecid & $P$ \\
\hline Oxalate $(n=5)$ & $5.2 \pm 0.7$ & $5.2 \pm 0.5$ & NS \\
PAH $(n=5)$ & $28.3 \pm 3.1$ & $2.8 \pm 0.5$ & $<0.001$ \\
\hline
\end{tabular}

* Values expressed as mean $\pm \mathrm{SEM}$; numbers in parentheses indicate number of animals.

gest that oxalate is nearly freely filterable at the glomerulus (13). In tubular fluid samples obtained from the early proximal tubule (defined here as $\mathrm{TF} / \mathrm{P}_{\text {inulin }}$ ratios of less than 2.0 ), the fractional delivery of oxalate was $120 \%$ of the filtered load, indicating net secretion. Separate analysis of the rate of delivery from the earliest accessible portion of the proximal tubule $\left(\mathrm{TF} / \mathrm{P}_{\text {inulin }}\right.$ ratios of $\left.1.25-1.5\right)$ was $118 \%$, implying that a secretory site for oxalate is present in the immediate postglomerular portion of the nephron. Comparisons of the fractional rates of oxalate delivery between the early and late portions of the proximal tubule indicated no net change in oxalate transport, but did not rule out the possibility of bidirectional transport. The results of the microinjection studies confirm that oxalate is reabsorbed in the accessible portions of the proximal tubule. The lack of a net change in transport in the presence of a reabsorptive flux implies a secretory flux of equal magnitude. The droplet precession studies indicate a secretory flux for oxalate but do not localize its nephron site. It is unlikely that there is any significant degree of oxalate transport in nephron segments other than the proximal tubule, since the fractional delivery rates from the late proximal tubule, distal tubule, and final urine did not differ. Moreover, oxalate microinjected into the most distal portions of the proximal tubule accessible to micropuncture was completely recovered in the final urine. It would appear, then, that oxalate undergoes net secretion in the early portions of the proximal tubule and bidirectional transport of equal magnitude in the mid-portions of the proximal tubule. Although the possibility of bidirectional transport is not definitely excluded, it would appear that there is little if any transport of oxalate at more distal nephron sites.

The presence of a secretory site for the organic acid oxalate in the early portions of the proximal convoluted tubule was a surprising finding, since the more distal portions of the proximal tubule, and especially the pars recta, are thought to be the major nephron sites of organic acid secretion. The possibility of a unique organic acid transport site, located in the early proximal tubule, was further examined by comparing the results obtained with oxalate with 
those obtained with the more traditional marker of organic acid secretion, PAH. As can be seen in Table II, the pattern of nephron contribution to PAH transport differed from that of oxalate in that net PAH secretion was initially evident only in later portions of the proximal tubule and most prominently in samples obtained from the distal tubule. The net addition of PAH between the late proximal tubule and distal tubule presumably reflects the contribution of PAH secreted by the pars recta (1). The calculated fractional delivery rates of PAH from each of the nephron sites examined and in the final urine in the current study are lower than those reported by Cortney and co-workers (6). Part of the discrepancy can be explained by the correction factor applied for plasma binding of $\mathrm{PAH}$, which has been estimated to be $10 \%$ (6). Preliminary studies in our laboratory indicate that plasma binding of PAH may be somewhat higher in individual experiments. If the current results are recalculated considering plasma binding to be $20 \%$, the average rates of fractional delivery of $\mathrm{PAH}$ are similar to those reported by Tanner and Isenberg (2). Even with these considerations, however, the discrepancy in the absolute values between the current study and those of Cortney et al. (6) remains and cannot be resolved at the present time.

The results of the present studies do not exclude the possibility of the presence of PAH secretion in the earliest portions of the proximal tubule, even at the nephron sites responsible for oxalate secretion. The marked differences in segmental contribution, however, suggest the possibility that the secretory sites for these two organic acids are different. In support of the suggestion that the secretory mechanism for oxalate and $\mathrm{PAH}$ are distinct were the differences in the changes in the measured parameters in response to probenecid. Probenecid did not affect net oxalate transport as determined in free-flow micropuncture studies, and was without effect on the results obtained in the microinjection and droplet precession studies. By contrast, probenecid clearly inhibited net $\mathrm{PAH}$ secretion, as evidenced by the decreased fractional delivery rate from the later portions of the proximal tubule and distal tubule and by the marked decrease in the $\left[{ }^{3} \mathrm{H}\right] \mathrm{PAH} /\left[{ }^{14} \mathrm{C}\right]$ inulin ratio of counts in the urine in the precession studies. In the early proximal tubule, probenecid decreased the fractional delivery rate from $88 \%$ to $80 \%$, and while a degree of inhibition of PAH secretion in this segment of the nephron cannot be definitely excluded, these values were not statistically different. Taken together, then, the results of these investigations indicate the existence of an organic acid secretory mechanism for oxalate which is located in the early portion of the proximal tubule and is distinct from that for PAH.

As indicated earlier, the pars recta is the nephron site most commonly associated with net transport of organic acids. By contrast, the secretion of the organic acid oxalate appears to occur in the early portion of the proximal tubule. Evidence has previously been advanced for the presence of an organic base secretory system in this portion of the nephron, although unequivocal evidence for organic acid secretion is not available (14). deRougemont and co-workers have suggested that the early postglomerular portion of the proximal tubule is the site of urate secretion and, in urate-loaded rats, net urate secretion was observed in micropuncture samples obtained from the early proximal tubule (15). These results with respect to urate have not been confirmed and have been questioned due to the methodologic difficulties in measuring the concentration of uric acid in nanoliter quantities of fluid $(16,17)$. The present studies with oxalate, on the other hand, support the concept that the early proximal tubule is important in the renal metabolism of some organic acids.

\section{ACKNOWLEDGMENTS}

We gratefully acknowledge the expert technical assistance of Ms. D. Steplock and Mr. Ernest Pace, the secretarial assistance of Ms. Polly Dunham, and the advice of Dr. Wadi N. Suki.

\section{REFERENCES}

1. Tune, B. M., M. B. Burg, and C. S. Patlak. 1969. Characteristics of $p$-aminohippurate transport in proximal renal tubules. Am. J. Physiol. 217: 1057-1063.

2. Tanner, G. A., and M. T. Isenberg. 1970. Secretion of $p$-aminohippurate by rat kidney proximal tubules. Am. J. Physiol. 219: 889-892.

3. Foulkes, E. C. 1963. Kinetics of $p$-aminohippurate secretion in the rabbit. Am. J. Physiol. 205: 1019-1024.

4. Häberle, D. 1975. Influence of glomerular filtration rate on the rate of para-aminohippurate secretion by the rat kidney: micropuncture and clearance studies. Kidney Int. 7: 385-396.

5. Yarger, W. E., H. S. Aynedjian, and N. Bank. 1972. A micropuncture study of postobstructive diuresis in the rat. J. Clin. Invest. 51: 625-637.

6. Cortney, M. A., M. Mylle, W. E. Lassiter, and C. W. Gottschalk. 1965. Renal tubular transport of water, solute, and PAH in rats loaded with isotonic saline. Am. J. Physiol. 209: 1199-1205.

7. Baines, A. D., C. W. Gottschalk, and W. E. Lassiter. 1968. Microinjection study of PAH excretion by rat kidney. Am. J. Physiol. 214: 703-709.

8. Weinman, E. J., G. Eknoyan, and W. N. Suki. 1975. The influence of the extracellular fluid volume on the tubular reabsorption of uric acid. J. Clin. Invest. 55: 283-291.

9. Weinman, E. J., D. Steplock, W. N. Suki, and G. Eknoyan. 1976. Urate reabsorption in proximal convoluted tubule of the rat kidney. Am. J. Physiol. 231: $509-515$.

10. Williams, H. E., G. A. Johnson, and L. H. Smith, Jr. 1971. The renal clearance of oxalate in normal subjects and patients with primary hyperoxaluria. Clin. Sci. $(O x f) .41:. 213-218$. 
11. McIntosh, G. H., and G. B. Belling. 1975. An isotopic study of oxalate excretion in sheep. Aust. J. Exp. Biol. Med. Sci. 53: 479-487.

12. Cattell, W. R., A. G. Spencer, G. W. Taylor, and R. W. E. Watts. 1962. The mechanism of the renal excretion of oxalate in the dog. Clin. Sci. (Oxf.). 22: 43-52.

13. Greger, R., F. Lang, H. Oberleithner, and P. Deetjen. 1977. Renal tubular transport of oxalate. (Abstract) Proceedings of the XXVI International Union of Physiological Science (IUPS) Congress, Paris, July 18-23. 283.

14. Ross, C. R., F. Diezi-Chomety, and F. Roch-Ramel. 1975.
Renal excretion of $N^{\prime}$-methylnicotinamide in the rat. $A m$. J. Physiol. 228: 1641-1645.

15. deRougemont, D., M. Henchoz, and F. Roch-Ramel. 1976. Renal urate excretion at various plasma concentrations in the rat: a free-flow micropuncture study. Am. J. Physiol. 231: 387-392.

16. Abramson, R. G., and M. F. Levitt. 1975. Micropuncture study of uric acid transport in rat kidney. Am.J. Physiol. 228: 1597-1605.

17. Weinman, E. J., and T. Knight. 1978. Renal tubular transport of urate. Mineral Electrolyte Metab. In press. 